Article

\title{
The Importance of Glycerophospholipid Production to the Mutualist Symbiosis of Trypanosomatids
}

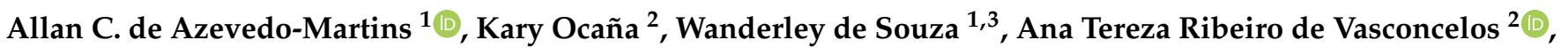 \\ Marta M. G. Teixeira ${ }^{4}$, Erney P. Camargo ${ }^{4}\left(\mathbb{D}\right.$, João M. P. Alves ${ }^{4, * \mathbb{D}}$ and Maria Cristina M. Motta ${ }^{1,3, *}$ \\ 1 Laboratório de Ultraestrutura Celular Hertha Meyer, Instituto de Biofísica Carlos Chagas Filho, \\ Universidade Federal do Rio de Janeiro, Rio de Janeiro 20000-000, RJ, Brazil; allan@biof.ufrj.br (A.C.d.A.-M.); \\ wsouza@biof.ufrj.br (W.d.S.) \\ 2 Laboratório Nacional de Computação Científica, Petropolis 25600-000, RJ, Brazil; karyann@lncc.br (K.O.); \\ atrv@lncc.br (A.T.R.d.V.) \\ 3 Instituto Nacional de Ciência e Tecnologia em Biologia Estrutural e Bioimagens, \\ Rio de Janeiro 20000-000, RJ, Brazil \\ 4 Departamento de Parasitologia, Instituto de Ciências Biomédicas, Universidade de São Paulo, \\ Sao Paulo 05508-000, SP, Brazil; mmgteix@icb.usp.br (M.M.G.T.); erney@usp.br (E.P.C.) \\ * Correspondence: jotajj@usp.br (J.M.P.A.); motta@biof.ufrj.br (M.C.M.M.)
}

\section{check for} updates

Citation: de Azevedo-Martins, A.C.; Ocaña, K.; de Souza, W.; Vasconcelos, A.T.R.d.; Teixeira, M.M.G.; Camargo, E.P.; Alves, J.M.P.; Motta, M.C.M. The Importance of Glycerophospholipid Production to the Mutualist Symbiosis of Trypanosomatids. Pathogens 2022, 11, 41. https:// doi.org/10.3390/pathogens11010041

Academic Editors: Maria

Carolina Elias and Olivier Sparagano

Received: 17 October 2021

Accepted: 28 December 2021

Published: 31 December 2021

Publisher's Note: MDPI stays neutral with regard to jurisdictional claims in published maps and institutional affiliations.

Copyright: (C) 2021 by the authors. Licensee MDPI, Basel, Switzerland. This article is an open access article distributed under the terms and conditions of the Creative Commons Attribution (CC BY) license (https:// creativecommons.org/licenses/by/ $4.0 /)$.

\begin{abstract}
The symbiosis in trypanosomatids is a mutualistic relationship characterized by extensive metabolic exchanges between the bacterium and the protozoan. The symbiotic bacterium can complete host essential metabolic pathways, such as those for heme, amino acid, and vitamin production. Experimental assays indicate that the symbiont acquires phospholipids from the host trypanosomatid, especially phosphatidylcholine, which is often present in bacteria that have a close association with eukaryotic cells. In this work, an in-silico study was performed to find genes involved in the glycerophospholipid (GPL) production of Symbiont Harboring Trypanosomatids (SHTs) and their respective bacteria, also extending the search for trypanosomatids that naturally do not have symbionts. Results showed that most genes for GPL synthesis are only present in the SHT. The bacterium has an exclusive sequence related to phosphatidylglycerol production and contains genes for phosphatidic acid production, which may enhance SHT phosphatidic acid production. Phylogenetic data did not indicate gene transfers from the bacterium to the SHT nucleus, proposing that enzymes participating in GPL route have eukaryotic characteristics. Taken together, our data indicate that, differently from other metabolic pathways described so far, the symbiont contributes little to the production of GPLs and acquires most of these molecules from the SHT.
\end{abstract}

Keywords: glycerophospholipids (GPLs); Symbiont Bearing Trypanosomatids (SHTs); symbiotic relationship; phospholipid metabolism; phylogenetic analysis

\section{Introduction}

Symbiosis means living together and represents a major driver in evolution. Symbiotic relationships occur between living beings of different species that co-evolve and constitute excellent models to understand the origin of organelles in the eukaryotic cell [1]. Nowadays, it is considered that symbiosis comprehends a full range of interactions, not only the beneficial ones but also neutral relations and even those in which one of the partners is harmed, such as parasitism. All trypanosomatid protozoa are parasites; only some are invertebrates (monoxenics), while others alternate between invertebrates and vertebrates (heteroxenics). Among the monoxenics, seven species pertaining to the Angomonas, Kentomonas, and Strigomonas genera (strigomonads) evolved through a mutualistic relationship with an intracellular bacterium referred to as Trypanosomatid Proteobacterial Endosymbiont (TPE), belonging to the Candidatus Kinetoplastibacterium genus [2,3]. This prokaryote is a gram-negative $\beta$-proteobacterium from the Alcaligenaceae family, and it is related 
to Achromobacter piechaudii, Taylorella equigenitalis, and some species from the Bordetella genus [2-5]. Another genus of symbiont-harboring trypanosomatids (SHTs) is Novymonas. In this case, the $\beta$-proteobacterium belongs to the Burkholderiaceae family and is important to the host-cell fitness although a small part of cultures is symbiont-free [6]. Considering that the eukaryotic cell with its structures resulted from the symbiosis between different primitive microorganisms [7], SHTs constitute interesting models to study cell evolution.

The presence of the symbionts in strigomonads is associated with ultrastructural alterations in the host trypanosomatid, such as an atypical microtubule array, a reduced paraflagellar rod, and a looser arrangement of the kinetoplast DNA network [8,9]. Furthermore, the symbiont is also related to modifications on the host surface charge and plasma membrane carbohydrate composition that somehow hampers the interaction and even impairs the insect host colonization by aposymbiotic trypanosomatids. Such strains were obtained after antibiotic treatment and are only maintained in vitro [10-13]. In the Angomonas and Strigomonas genera, predictions from genome annotations were consistent with the first biochemical descriptions, showing that the symbiont completes essential biosynthetic routes of the host cell, such as those for heme, amino acid, and vitamin production $[10,14-20]$. It means that SHTs present very low nutritional requirements and reduced growth rates when compared to trypanosomatids that naturally do not contain the symbiont and are usually referred to as regular trypanosomatids (RTs).

In fact, the endosymbiosis in trypanosomatids has been characterized by two-way metabolic changes. In this sense, the TPE enhances the mitochondrion's oxidative phosphorylation and induces an increase in energy production by making the metabolic link between glycosomes and the mitochondrion. The result of the interaction between these three cell structures is the increased production but also the higher consumption of ATP. There are indications that this integrated metabolism benefits the bacterium, which is able to use part of the generated metabolites to build its own carbon skeleton [21,22]. The presence of the TPE also increases host phospholipid production, especially for phosphatidylcholine (PC). Once isolated from the host cell, the bacterium is able to survive for $3 \mathrm{~h}$ and to produce phospholipids in media containing $\left[{ }^{32} \mathrm{P}\right]$-orthophosphate. However, the PC amounts in the free symbiont are markedly reduced when compared to those measured in the intracellular bacterium, thus indicating that this prokaryote may obtain most of its PC from the host trypanosomatid [23].

The glycerophospholipids (GPL) are amphipathic molecules composed by hydrophilic head groups linked via phosphate to glycerol-bound fatty acid or fatty alcohol chains. GPLs are present in both eukaryotic and prokaryotic cells and have structural and metabolic functions. They play essential roles as membrane constituents, regulating protein structure and function as well as the formation of specialized membrane domains [24,25]. Furthermore, GPLs are involved in cell cycle and signaling, including in trypanosomatids [26-29]. In the Trypanosoma and Leishmania genera, PC and phosphatidylethanolamine (PE) are present in higher amounts, followed by phosphatidylinositol (PI), while phosphatidylserine (PS), phosphatidylglycerol (PG), and cardiolipin (CL) are present in minor quantities [30-34]. Similarly, in the SHT Angomonas deanei, biochemical analysis showed that the major phospholipids are PC and PE, however PI and CL are present in similar quantities that correspond to those found in RTs [35].

The symbiotic bacterium of $A$. deanei presents CL as the major phospholipid, followed by equal amounts of PC and PE and minor quantities of PI [35]. PC is unusual in prokaryotes, which usually contain PG as the main structural phospholipid in membranes, except in those that maintain a close symbiotic or pathogenic relationship with eukaryotic cells [36-41]. PI is also involved in symbiotic interactions by regulating intracellular calcium levels in the host in a phosphoinositide-dependent signaling pathway, as reported in Rhizobium-legume symbiosis [42,43]. In A. deanei, genome analyses and phylogenetic data showed that sequences for PI biosynthesis were absent in the symbiont, thus indicating that the bacterium depends on the host to obtain PI [44]. 
In this work, we performed in-silico identification and phylogenetic analysis of the genes involved in glycerophospholipid synthesis considering strigomonad SHTs and their respective symbionts as well as other members of the family that naturally do not contain the symbiotic bacterium. The symbiont but not the host trypanosomatid has the gene that converts phosphatidylglycerol phosphate (PGP) to PG. Furthermore, the bacterium contains genes that may enhance the host production of phosphatidic acid (PA), which is essential for the construction of glycerophospholipids. Such sequences are also present in SHTs and have eukaryotic origin. However, most genes of the metabolic pathways using dihydroxyacetone phosphate (DHAP) and glycerol-3-phosphate (G3P) to produce PS, PE, PG, and CL are complete in the host trypanosomatid genome but absent in the symbiont. Here, our genomic data indicate that the symbiont seems to depend on the host cell for obtaining most glycerophospholipids that constitute its membranes.

\section{Results}

\subsection{TPE Phylogenies}

TPE sequences for G3P dehydrogenase (Figure S1) cluster and share two common ancestors with two Bordetella species. Sequences for lysophosphatidate acyltransferase and PA citidyltransferase (Figures S2 and S3), involved in the production of CDP-diacylglycerol from G3P, and the sequences of phosphatidylglycerophosphatase (Figure S4), which produces PG from PGP, present a common ancestor for TPE and bacteria of the Taylorella genus. These sequences cluster in a distant branch from the Achromobacter and Bordetella genera due to the divergence between sequences. In phylogenetic trees for PGP synthase and PS decarboxylase (Figures S5 and S6), the symbiont is positioned as a basal group in the Alcaligenaceae family.

\subsection{RT and SHT Phylogenies}

Most of the trypanosomatid enzymes involved in phospholipid synthesis analyzed here presented no sign of horizontal gene transfer (data not shown), but a few of them have more ambiguous scenarios.

G3P dehydrogenase (1.1.1.8 and 1.1.5.3) was found in many trypanosomatids as well as Bodo saltans, plus a few other eukaryotes (Figure 1 and Figure $\mathrm{S} 7$ for close-up details). The 1.1.1.8 tree is mainly composed by bacteria (mostly Deltaproteobacteria and Nitrospirae). The other Eukaryota in this tree are all near the Kinetoplastida, including the unexpected grouping of $B$. saltans with the alveolate Perkinsus marinus, with bootstrap support value (BSV) of 70. The few other eukaryotes clustering with the trypanosomatids with high BSV (100) are from diverse parts of the tree of eukaryotes: Vitrella brassicaformis (Alveolata), Ectocarpus silicosus (Phaeophyceae, brown alga), and Sphaeroforma antarctica (Ichthyosporea, near animals).

The sister group of these eukaryotes in the tree, with BSV of 86, is composed of one unclassified Proteobacteria and one unclassified Deltaproteobacteria. All other nearby clades in the tree present very low statistical support and therefore do not allow for any confident definition of a more exact placement of this trypanosomatid enzyme in the tree. The only other eukaryotes present in the 1.1.1.8 tree are a group of three green algae; they are relatively near the trypanosomatid clade, but with very low BSV; therefore, their placement is not conclusive.

The tree for G3P oxidase (Figures 2 and S8) presents two clades of trypanosomatids: a larger one containing most trypanosomatids, including Trypanosoma, Bodo, and Perkinsela; and a smaller one, comprised of mostly Leishmania but also containing one T. theileri and a few Leptomonas, Strigomonas, and Angomonas sequences. Since the two clades are located in two different subtrees separated by a long branch, it is possible that the two clades are either different families performing the same function (G3P oxidase) or different but related functions, and hence, the sequence similarity allows for the selection and alignment of both groups. Closer inspection of RPSBLAST search results (against the Conserved Domain Database of NCBI) representative couples, one eukaryotic and one bacterial, from 
each of these two clades, suggests these are indeed two separate families of 2-hydroxyacid phosphoglycerate dehydrogenases since the domains identified have the same functions but different sequences (data not shown).

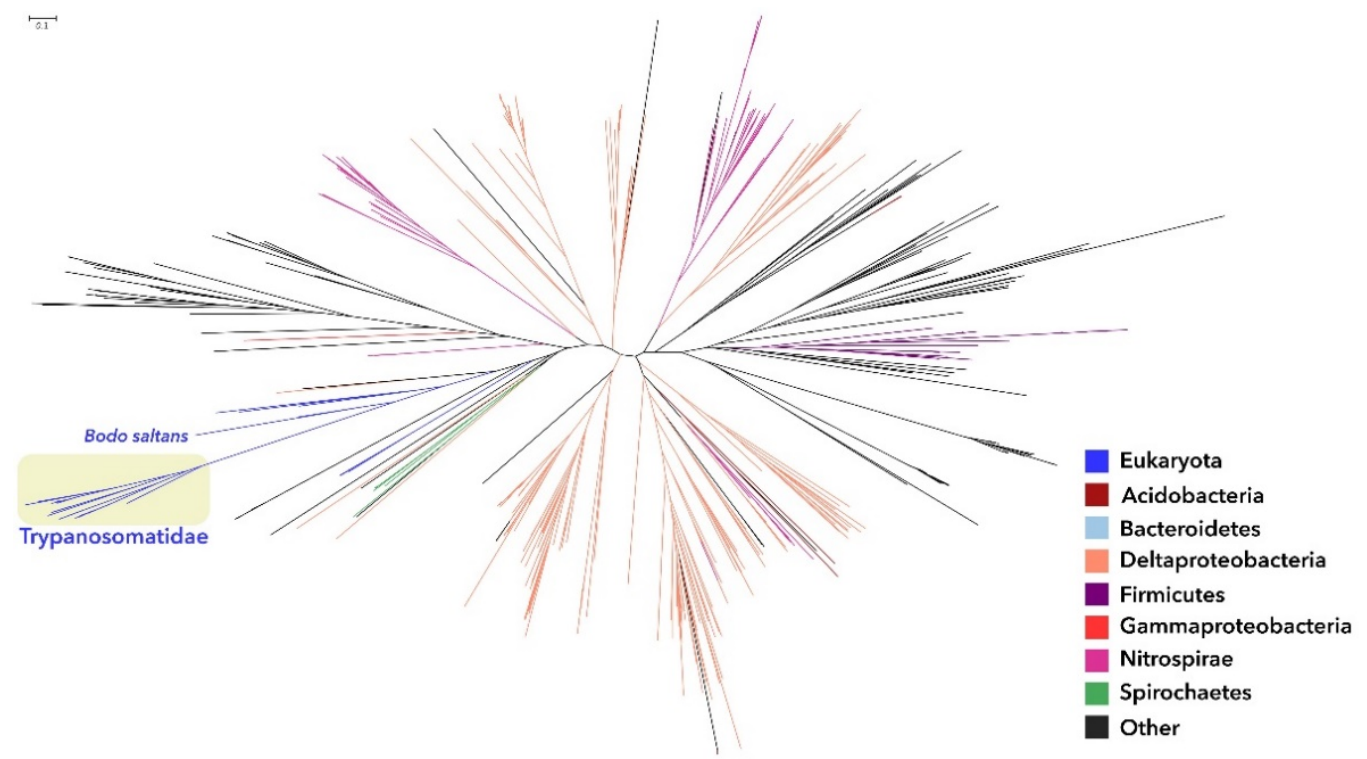

Figure 1. Maximum likelihood phylogenetic tree for enzyme glycerol-3-phosphate dehydrogenase (1.1.1.8), using $L$. major sequence as the query for sequence selection. Branch colors identify taxonomic affiliation as detailed in the legend. Close-up details of the areas containing the trypanosomatid sequences can be seen in Figure S1. Schemes follow the same formatting.

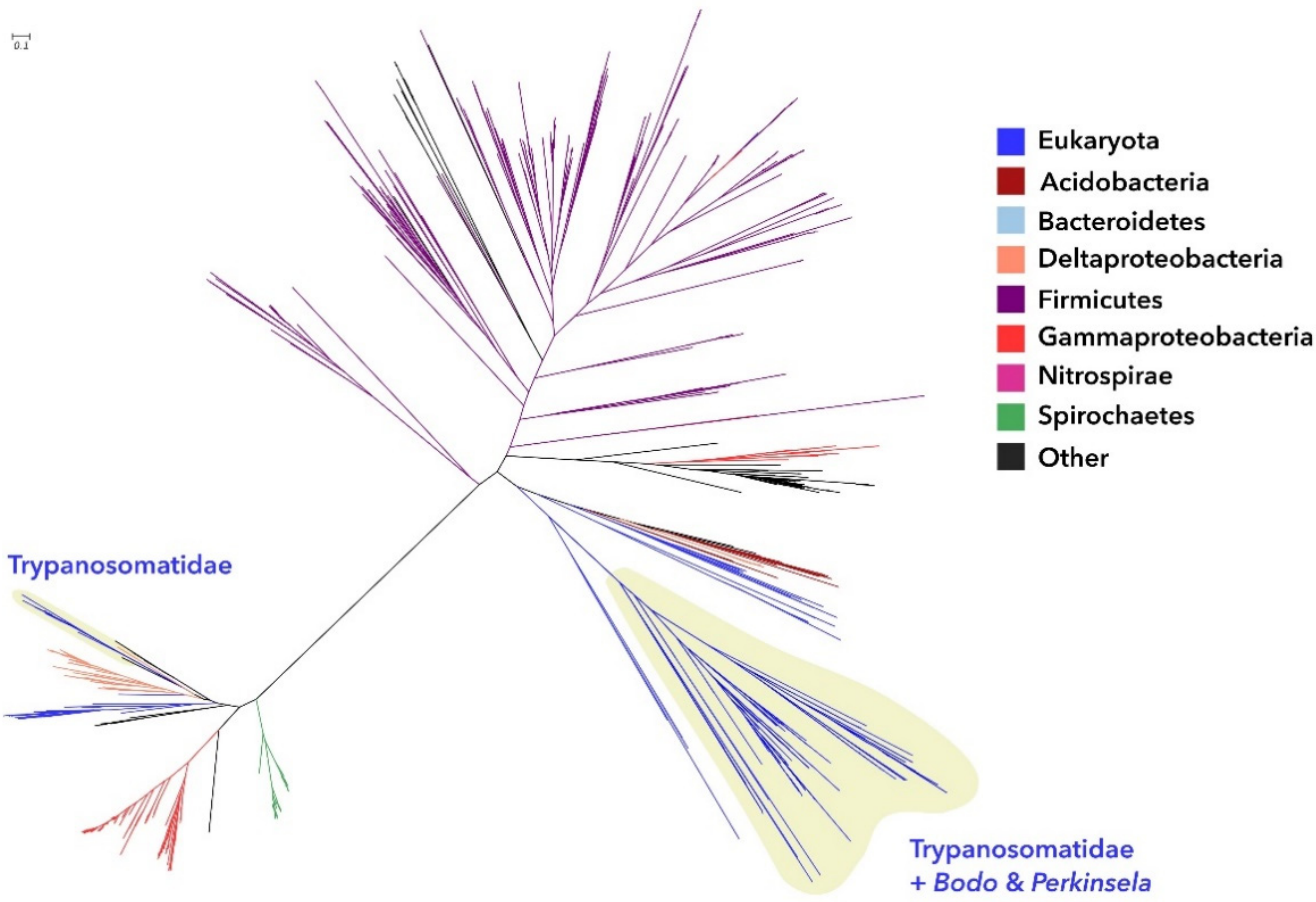

Figure 2. Maximum likelihood phylogenetic tree for enzyme glycerol-3-phosphate oxidase (1.1.3.21), using $L$. major sequence as the query for sequence selection. Branch colors identify taxonomic affiliation as detailed in the legend. Close-up details of the areas containing the trypanosomatid sequences can be seen in Figure S2.

It is interesting to notice that the large clade contains two groups of Strigomonadinae sequences, one in their expected placement near the Leishmaniinae and another (composed 
of just A. deanei and S. culicis sequences as well as one Leptomonas pyrrhocoris sequence) as an outgroup to all other Kinetoplastida sequences, including B. saltans and Perkinsela sp.

As seen for the G3P dehydrogenase, the G3P oxidase tree is mainly composed of enzymes from bacteria (Firmicutes, Gammaproteobacteria, Spirochaetes, and Deltaproteobacteria), being the most represented groups, but there are more eukaryotic groups present. In the large clade, the Eukaryota are near each other although with very low BSV, which does not allow for confident placement. The sister group of the Kinetoplastida clade in this subtree is comprised of two Ciliates (Pseudocohnilembus and Oxytricha) and one dinoflagellate (Symbiodinium), with BSV of 58. More distantly, and with insignificant statistical support, there is a small group of Apicomplexa, plants, and Stramenopiles intermingled with Bacteria, mostly Deltaproteobacteria and Acidobacteria. The fourth and final clade containing Eukaryota is in the smaller subtree, and it does not cluster close to the trypanosomatids in that subtree.

The PA cytidylyltransferase tree (Figures 3 and S9) presents a similar situation to that for enzyme G3P oxidase, whose tree is divided in two subtrees separated by a long branch, indicating that at least two different gene families are involved. One of the subtrees is comprised of Eukaryota and contains a diverse group of Kinetoplastida, including Bodo and Perkinsela as well as many Trypanosomatidae genera. The other subtree contains almost only Bacteria, mainly Firmicutes and Bacteroidetes, but also a large group of Trypanosomatidae. However, this clade is better said to be in-between the two subtrees and does not cluster with good statistical support with any bacterial group. Therefore, it is not possible to conclude whether this is a very different variant of PA cytidylyltransferase that is exclusive to trypanosomatids or the result of an ancient horizontal gene transfer.

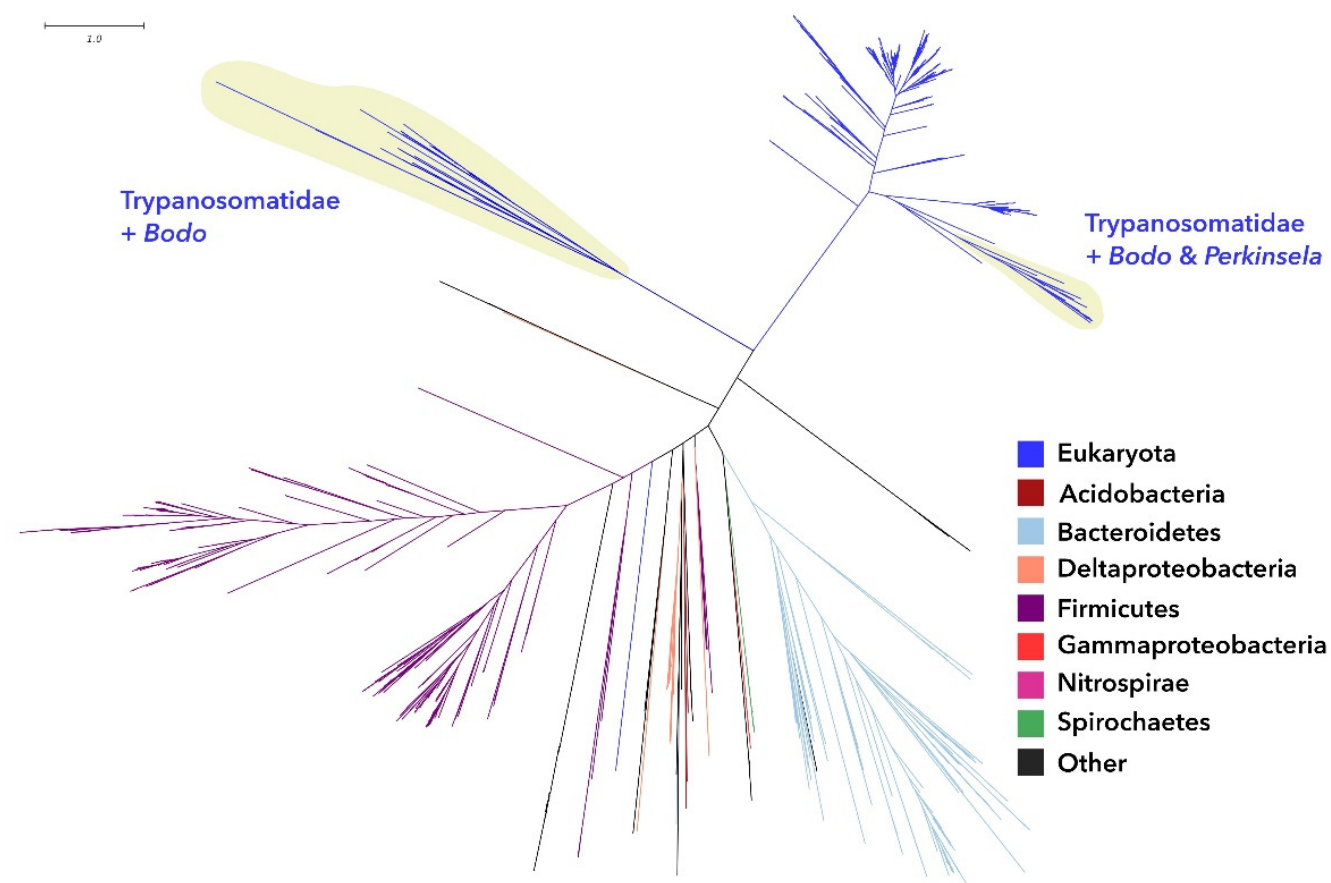

Figure 3. Maximum likelihood phylogenetic tree for enzyme phosphatidic acid cytidylyltransferase (2.7.7.41), using L. major sequence as the query for sequence selection. Branch colors identify taxonomic affiliation as detailed in the legend. Close-up details of the areas containing the trypanosomatid sequences can be seen in Figure S3.

\section{Discussion}

Symbiotic relationships constitute excellent models for the study of cell evolution, such as the origin of organelles. In symbioses that have been investigated so far, it is common to observe a modulation of lipid metabolism on both partners. In the association of sea anemones and corals with Symbiodinium, the dinoflagellate influences the fatty acid 
composition of the host lipid bodies [45-54]. There are also reports showing the influence of symbionts in the host-cell membrane phospholipids in beneficial or pathogenic associations. For example, in relationships between prokaryotes and eukaryotes, PC, a GPL usually absent in prokaryotes, is present in the membrane of Pseudomonas aeruginosa, Brucella abortus, and Agrobacterium tumefaciens [55-57]. Another case is the symbiotic relationship between leguminous plants and the symbiotic bacterium Rhizobium leguminosarum, where there is an increase in PI 4-phosphate content in the host plant, which is necessary for the root nodulation process to occur [58]. Still regarding GPLs, some intracellular pathogens, such as those from the Yersinia genus, have mechanisms to subvert the phosphoinositide metabolism, altering the amounts of PI, PIP, and PIP2 in the host in order to promote or to block their internalization in cells of different tissues [59].

Although the amount of GPLs varies in eukaryotes and prokaryotes, their membranes have a very similar biochemical structure, consisting of G3P, a phosphorylated alcohol, linked to two acyl chains [60]. This results in PA production, a molecule that is initially synthesized in the ER membrane of eukaryotes and represents an important component in establishing the mutualistic relationship between Rhizopus microsporus fungi and Burkholderia endobacteria [61]. In trypanosomatids, such as A. deanei and other strigomonad SHTs analyzed in this work, sequences for enzymes that use DHAP for PA synthesis are present in the genome. This pathway that contains three chemical reactions is catalyzed in the first step by one enzyme (a G3P dehydrogenase (1.1.1.8 or 1.1.5.) or G3P oxidase (1.1.3.21)) to produce G3P, followed by addiction of acyl chains to G3P molecule by G3P acyltransferase to produce PA (Figures 4 and S10).

In strigomonad trypanosomatids, the symbiont has the gene for G3P dehydrogenase enzyme (1.1.1.94), which uses DHAP for G3P synthesis, indicating the relevance of G3P to the bacterium and corroborating data on the ability of SHTs to ferment. Such protozoans prioritize carbohydrate consumption in glucose-enriched media, producing large amounts of G3P when oxidative phosphorylation is inhibited by $\mathrm{KCN}$ [22]. In the symbiosis between fungi and bacteria, G3P is involved not only in energy metabolism but especially in GPL biosynthesis, which is regulated by the Hog1 MAPK pathway [61]. Considering the course of evolution, this fermentative activity represents a possibility of an alternative energy supply in relation to oxidative phosphorylation since trypanosomatids diverged very early from the last eukaryotic common ancestor [62].

PA production also seems to be possible in symbiotic SHT bacteria since the gene of a G3P acyltransferase (2.3.1.51), which converts Lyso-PA to PA, is present. As stated earlier, in corals, the Symbiodinium endosymbiont has the ability to influence the composition of PA fatty acids found in lipid bodies and other host structures [63]. It is noteworthy that PA can be dephosphorylated into diacylglycerol (DAG) by enzyme PA phosphatase (3.1.3.4) and vice versa by enzyme DAG kinase (2.7.1.107). Genes for both enzymes PA phosphatase and DAG kinase were identified in endosymbionts and in host trypanosomatids (Figures 4 and S10). These two molecules, PA and DAG, represent starting points from which the GPL metabolic pathways branch out, resulting in the production of different types of phospholipids $[60,64]$.

DAG is used to produce PC and PE by the Kennedy pathway through a condensation reaction with the radical, choline, or ethanolamine, respectively. An assumption is that this pathway, present in the ER, uses exogenous Lyso-PE or Lyso-PC so that the trypanosomatid could obtain ethanolamine or choline from the external environment. Genes for enzymes involved in PE and PC production showed high similarities between protozoa species, such as T. cruzi and Plasmodium falciparum $[65,66]$. Genes for the Kennedy pathway were not identified in strigomonad TPEs (Figure 4). 


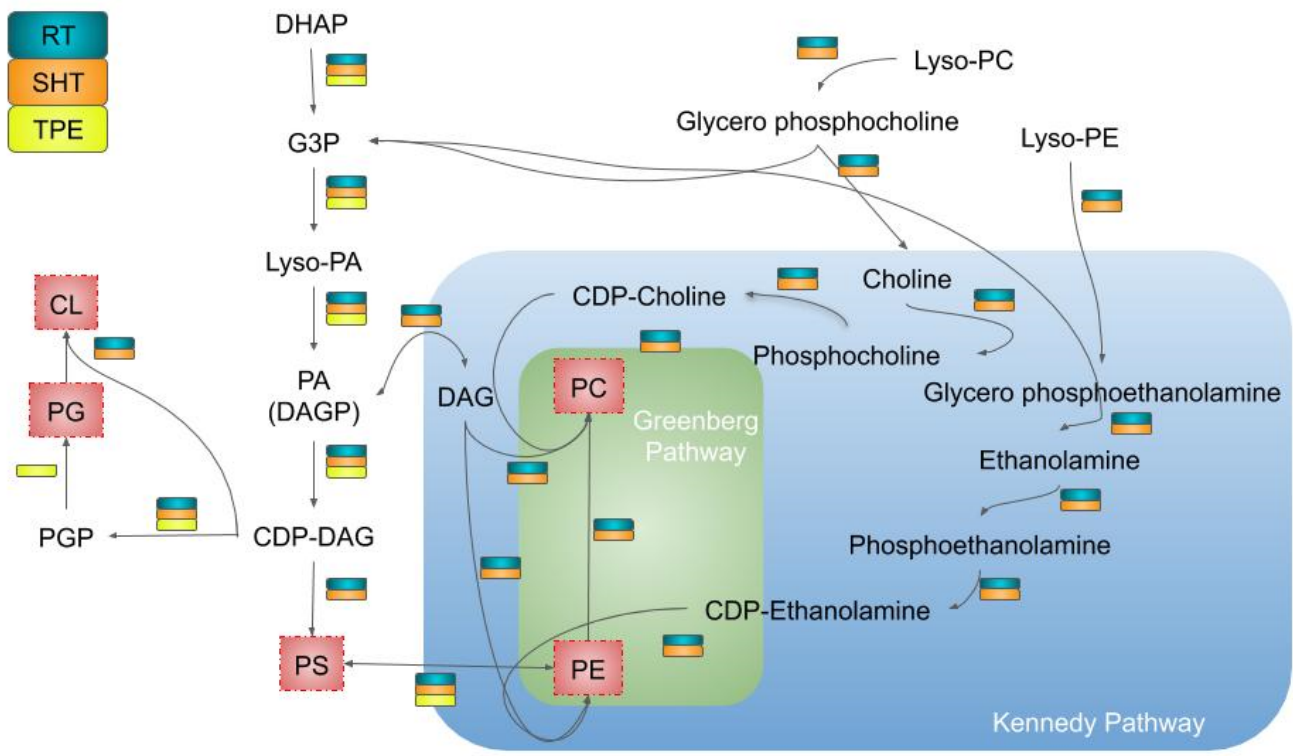

Figure 4. Glycerophospholipid (GPL) metabolism in regular trypanosomatids (RT), symbiont harboring trypanosomatid (SHT), and trypanosomatid proteobacterial endosymbiont (TPE). The scheme summarizes the metabolic pathways of GPL synthesis considering the genes identified in RT, SHT, and Candidatus Kinetoplastibacterium crithidii (A. deanei symbiont). The synthesis of GPL can use metabolic intermediates, such as DHAP and G3P, for the synthesis of PA, a central molecule in the metabolism of GPL. In RTs and SHTs, CDP-DAG is produced from PA, thus enabling the synthesis of zwiterionic GPL (PS, PE, and PC) or the production of PGP. It is important to note that in these organisms, the synthesis of CL does not pass through PGP but occurs through the metabolites CDP-DAG and PG to form CL. Differently, the TPE can use PGP to produce PG, but genes encoding prokaryotic enzymes that produce CL have not been found. RT and SHT present genes for PC synthesis from PE methylation through the Greenberg pathways (highlighted in the green background) and through de-novo synthesis via the Kennedy pathway (highlighted in the blue background). PE can be produced from the Kennedy pathway or in reverse from PS (the latter path was also identified in the symbiont). One possibility is that a phospholipase D (PLD) could act on the metabolism of lyso-PC and lyso-PE molecules, which could be obtained from the environment and used as a source to produce GPL. For detailed identification of enzymes and molecules of these pathways, check Table S1 and Figure S10. CL, cardiolipin; DAG, diacylglycerol; DAGP, diacylglycerol phosphate; DHAP, dihydroxyacetone; G3P, glycerol 3 phosphate; Lyso-PA, lyso-phosphatidic acid; Lyso-PC:, lso-phosphatidylcholine; Lyso-PE, lyso-phosphatidylethanolamine; PA, phosphatidic acid; PC, phosphatidylcholine; PE, phosphatidylethanolamine; PG, phosphatidylglycerol; PGP, phosphatidylglycerolphosphate; PS, phosphatidylserine; RT, regular trypanosomatids; SHT, symbiont harboring trypanosomatids; TPE, trypanosomatid proteobacterial endosymbiont.

The Greenberg pathway is also present in trypanosomatids; in this case, three successive PE methylations generate PC, the major GPL of eukaryotic cell membranes. Although it is known that in eukaryotes, more than one PE N-methyltransferase (2.1.1.17) participates in this route, we have identified only one gene for this enzyme in $A$. deanei. It is possible that this single enzyme is catalyzing the three methylations, thus producing PC, as described in L. major, which contains the LmjPEM2 gene [67]. In strigomonad TPEs, as expected for prokaryotes, we did not identify genes for this pathway (Figure 4).

In addition to DAG, PA is also a starting point for GPL production. The first step is the conversion of PA to CDP-DAG by the enzyme PA cytidylyltransferase (2.7.7.41). From there, CDP-DAG can be used to produce PS by the enzyme CDP-DAG-serine phosphatidyltransferase (2.7.8.8), whose gene has been identified in the trypanosomatids and symbionts analyzed in this work. The presence of this sequence suggests that the PS production pathway occurs in the protozoan ER. In addition, we have also identified the enzymes PS 
synthase 2 (2.7.8.29) and PS decarboxylase (4.1.1.65) genes, whose activities result in the conversion of PS to PE and vice versa, thus regulating the cellular levels of such GPLs. Interestingly, the enzyme PS decarboxylase (4.1.1.65) is located in mitochondria, whereas enzymes CDP-DAG-serine phosphatidyltransferase (2.7.8.8) and PS synthase 2 (2.7.8.29) are located in the ER (Figure 5). It has been reported that contact regions between ER and mitochondria, referred to as ER-Mitochondria Encounter Structure (ERMES), permit the regulation of PS and PE content in ER [68]. The proximity between these organelles and the symbiont suggests that the bacterium may play a mitochondrial-like role in the recycling of PS into PE for its own use or even in the supply to the host trypanosomatids (Figure 5).

Another important point to discuss concerns the possible influence of the symbiont on CL production, a GPL that confers high permeability selectivity in membranes. In eukaryotes, $\mathrm{CL}$ is present in great amounts in the mitochondrial inner membrane, and its biosynthesis is the result of a biochemical reaction promoted by phosphatidyltransferase, also called as cardiolipin synthase (CLS), a phosphatidyltransferase that condenses PG with the Lyso-PA grouping of a CDP-DAG molecule [69]. In prokaryotes, CL plays an important role in forming an ion barrier and establishing a stable membrane domain for the insertion of respiratory complexes [70,71]. In this case, CL synthesis occurs from the condensation of two PGs by the action of a D-like phospholipase [69]. Searches in SHT genomes indicate the presence of genes for the enzyme CDP-DAG-G3P phosphatidyltransferase (2.7.8.5, which uses CDP-DAG to produce PGP) and CLS (uses PG to produce CL). However, the gene for the enzyme phosphatidylglycerophosphatase (3.1.3.27) was not identified. This enzyme is in an intermediate step in the conversion of PGP into PG and was only found in the symbiont (Figures 4 and S10). Taken together, these findings suggest that the host protozoan would be able to produce CL without necessarily producing the PG precursor but also indicate that the symbiotic bacteria could provide part of the required PG that can be used by the host to produce CL, an essential component of the mitochondrial inner membrane. It is worth mentioning that the presence of the symbiotic bacteria increases the phosphorylative capacity of the host cell $[21,22]$.

Phylogenetic analyses revealed that most of the trypanosomatid enzymes involved in phospholipid synthesis analyzed here presented no sign of horizontal gene transfer, but a few of them have more ambiguous scenarios. The enzyme G3P dehydrogenase (1.1.1.8) was found in trypanosomatids, in Bodo saltans, and few other eukaryotic species. The observation that eukaryotes present in the G3P dehydrogenase tree are clustering near each other and, without any sign of artifacts, such as long-branch attraction, suggests that they inherited the enzyme from a common ancestor, while all other eukaryotes lost this particular orthologue. It is not clear why so few and so distantly related groups would retain this version of the enzyme. Another interesting point was the phylogenetic analysis for enzymes G3P oxidase (1.1.3.21) and PA cytidylyltransferase (2.7.7.41) since they grouped trypanosomatids in two clades that are located in two different subtrees separated by a long branch. It is possible that the two clades are either different families performing the same enzyme function or distinct but related functions. Phylogenetic analyses showed that enzymes involved in GPL synthesis positioned symbionts of trypanosomatids as a basal group in the Alcaligenaceae family. Sequences for CDP-DAG and PG production showed a common ancestor for TPEs and bacteria of the Taylorella genus, which is in accordance to previous evolutionary data using genomic and phylogenomic analysis [4].

Endosymbionts of trypanosomatids have a very small but highly functional genome [20]. Previous studies showed that these bacteria contain most genes to produce heme, amino acids, and vitamins, thus completing SHT essential metabolic pathways [17-19]. In addition, the presence of prokaryotes modulates the expression of host genes, especially those involved in energy metabolism, an important aspect for understanding the co-evolution in SHTs [72,73]. In this work, we found that the symbiont contains few genes to produce GPLs; however, those that are present contribute to the production of phospholipids, such as PG and $\mathrm{CL}$, that seem relevant for the maintenance of symbiont-trypanosomatid mutualistic relationship. The absence of bacterial genes for PC production in the symbiont reinforces 
the relevance of this GPL in the process of interaction between prokaryotes and eukaryotes; thus, the host could control bacterial growth and division [40].

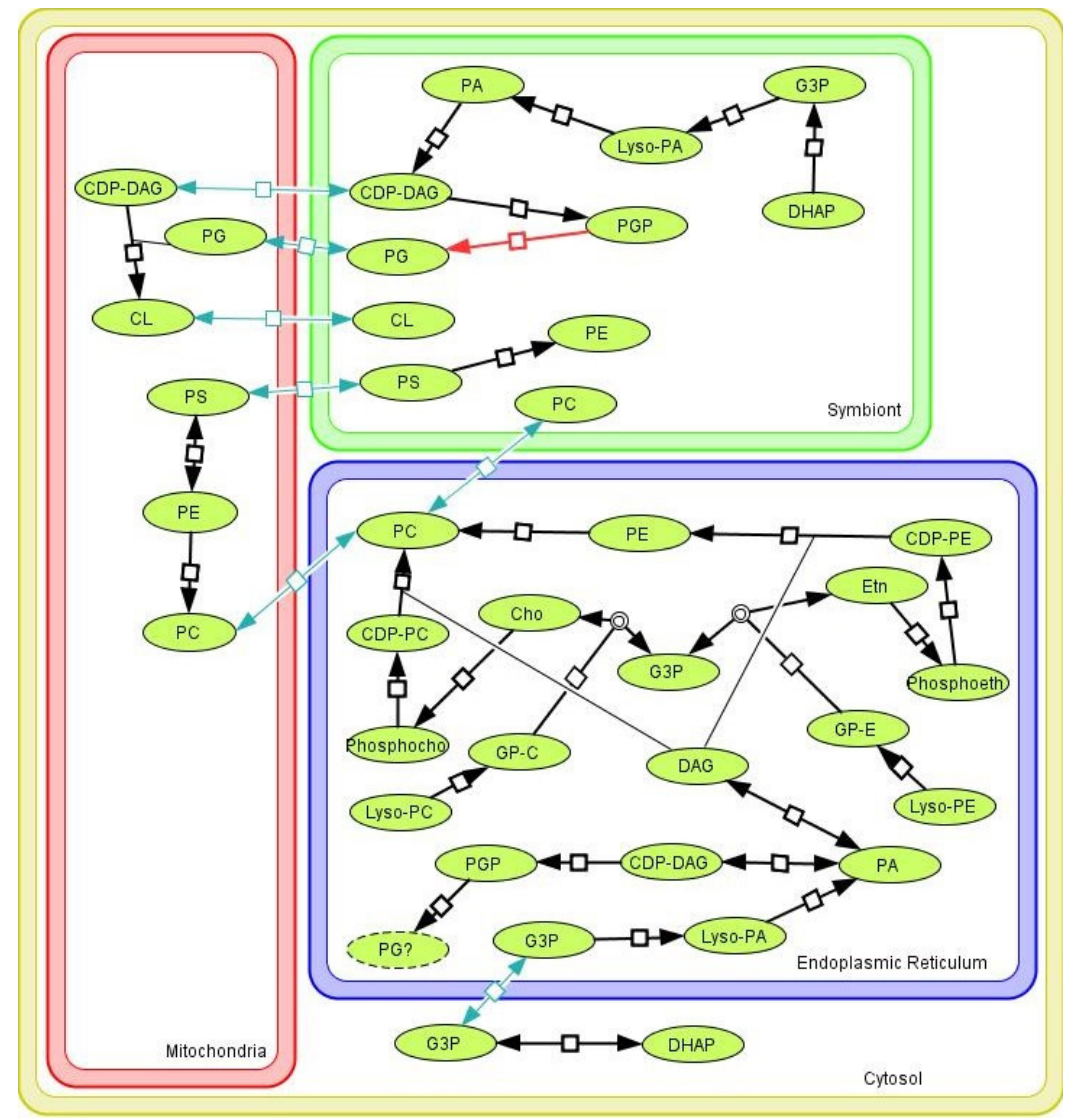

Figure 5. Glycerophospholipid (GPL) metabolism pathways in symbiont harboring trypanosomatids (SHTs) considering different cell compartments. The figure presents the reactions of GPL metabolism localized in the cytosol (yellow compartment), endoplasmic reticulum (blue compartment), mitochondrion (red compartment), and the symbiont (trypanosomatid proteobacterial endosymbiont; TPE, green compartment). Black arrows indicate enzyme reactions identified in genome searches. Regarding PG formation in the SHT endoplasmic reticulum (represented with dotted line), the enzyme that catalyzes its synthesis from PGP in the final step was found neither in SHT nor in regular trypanosomatids (RT) genomes but in the symbiont (red arrow). It is possible that the PG produced in the TPE could be exported to the mitochondrion to enhance CL synthesis in this organelle. Then, CL could be imported by the TPE, which is unable to produce this GPL. In addition, TPEs present a reversible reaction to produce PS from PE, which would regulate both GPL amounts. Green arrows suggest how compartments share GPL molecules. For detailed identification of enzymes and molecules of these pathways, check Table S1. CL, cardiolipin; CDP-DAG, CDP-diacylglycerol; CDP-PC, CDP-phosphatidylcholine; CDP-PE, CDP-phosphatidylethanolamine; DAG, diacylglycerol; DHAP, dihydroxyacetone; G3P, glycerol 3 phosphate; GP-C, glycerophosphocholine; GP-E, glycerophosphoethanolamine; Lyso-PA, lyso-phosphatidic acid; Lyso-PC, lyso-phosphatidylcholine; LysoPE, lyso-phosphatidylethanolamine; PC, phosphatidylcholine; PE, phosphatidylethanolamine; PG, phosphatidylglycerol; PGP, phosphatidylglycerolphosphate; PS, phosphatidylserine; Phosphocho, phosphocholine; Phosphoeth, phosphoethanolamine; RT, regular trypanosomatids; SHT, symbiont harboring trypanosomatids; TPE, trypanosomatid proteobacterial endosymbiont.

In-silico data generated here reinforce the idea previously obtained through biochemical analysis that the bacterium GPLs are mainly obtained from the host protozoan. Such results are relevant since they suggest that this phenomenon occurs in different species of strigomonads. More recently, it was shown in A. deanei that gene expression can be 
modulated by RNA interference and that the CRISPRCas9 gene deletion system is active in this protozoan $[74,75]$. Thus, the present study is very promising for future investigations, indicating how interfere in glycerophospholipid synthesis pathways and revealing the contribution of these molecules to the symbiotic relationship maintenance.

\section{Materials and Methods}

\subsection{Genomic Analysis}

For genomic analysis, protein sequences involved in GPL synthesis were identified by Enzyme Commission (EC) number (Table S1), collecting candidate orthologs from several organisms considering strigomonad SHTs and their respective TPEs. In order to ensure that $A$. deanei and its symbiont, named $C a$. K. crithidii, presented the target genes, we first searched the sequences by EC number in L. major in the TriTrypDB database [45] and Escherichia coli in NCBI's non-redundant (nr) protein database. Then, we searched the A. deanei and Ca. K. crithidii genomes for these sequences. and each sequence identified was used to create one dataset.

The strigomonad SHT and RT datasets, identified by EC number, are the results of BLASTP searches against the NCBI's nr database, collecting up to five hundred (for less conserved sequences) to a thousand sequences (for more conserved ones) that passed the maximum threshold E-value of $1 \times 10^{-10}$.

\subsection{Phylogenetic Analysis}

For TPEs, 18 GPL enzyme sequence datasets were created using Betaproteobacteria as reference: six were found in at least two TPEs and were used for phylogenetic analysis, whereas the other 12 sequences could not be used for this purpose (Table 1). For trypanosomatids, 21 datasets were created (Table 2).

Table 1. GPL enzyme gene sequences found in the TPEs used for phylogenetic analysis.

\begin{tabular}{|c|c|c|c|}
\hline E.C. & TPE & Accession & Evolutionary Model \\
\hline 1.1.1.94 & $\begin{array}{c}\text { Ca. K. blastocrithidii } \\
\text { Ca. K. crithidii } \\
\text { Ca. K. desouzaii } \\
\text { Ca. K. oncopeltii }\end{array}$ & $\begin{array}{l}\text { WP_015390063.1 } \\
\text { WP_015238735.1 } \\
\text { WP_015396598.1 } \\
\text { WP_015397299.1 }\end{array}$ & $W A G+G$ \\
\hline 2.3.1.51 & $\begin{array}{c}\text { Ca. K. blastocrithidii } \\
\text { Ca. K. crithidii } \\
\text { Ca. K. desouzaii } \\
\text { Ca. K. galatii } \\
\text { Ca. K. oncopeltii }\end{array}$ & $\begin{array}{l}\text { WP_015390063.1 } \\
\text { WP_015389151.1 } \\
\text { WP_015396525.1 } \\
\text { WP_015389750.1 } \\
\text { WP_015397233.1 }\end{array}$ & $\mathrm{WAG}+\mathrm{G}+\mathrm{F}$ \\
\hline 2.7.7.41 & $\begin{array}{c}\text { Ca. K. crithidii } \\
\text { Ca. K. desouzaii } \\
\text { Ca. K. galatii } \\
\text { Ca. K. oncopeltii } \\
\text { Ca. K. sorsogonicusi }\end{array}$ & $\begin{array}{c}\text { WP_015389094.1 } \\
\text { WP_015396290.1 } \\
\text { WP_015389515.1 } \\
\text { WP_015397011.1 } \\
\text { AWD32429.1 }\end{array}$ & $\mathrm{WAG}+\mathrm{I}+\mathrm{G}+\mathrm{F}$ \\
\hline 2.7 .8 .5 & $\begin{array}{c}\text { Ca. K. blastocrithidii } \\
\text { Ca. K. crithidii } \\
\text { Ca. K. desouzaii } \\
\text { Ca. K. galatii } \\
\text { Ca. K. oncopeltii } \\
\text { Ca. K. sorsogonicusi }\end{array}$ & $\begin{array}{c}\text { WP_015238268.1 } \\
\text { WP_015389066.1 } \\
\text { WP_015396149.1 } \\
\text { WP_015389380.1 } \\
\text { WP_015396882.1 } \\
\text { AWD32310.1 }\end{array}$ & $\mathrm{CPREV}+\mathrm{G}+\mathrm{F}$ \\
\hline 3.1.3.27.A & $\begin{array}{c}\text { Ca. K. blastocrithidii } \\
\text { Ca. K. crithidii } \\
\text { Ca. K. desouzaii } \\
\text { Ca. K. galatii } \\
\text { Ca. K. oncopeltii }\end{array}$ & $\begin{array}{l}\text { WP_015237959.1 } \\
\text { WP_015238600.1 } \\
\text { WP_015396243. } \\
\text { WP_015389467.1 } \\
\text { WP_015396965.1 }\end{array}$ & $\mathrm{CPREV}+\mathrm{G}+\mathrm{F}$ \\
\hline
\end{tabular}


Table 1. Cont.

\begin{tabular}{cccc}
\hline E.C. & TPE & Accession & Evolutionary Model \\
\hline & Ca. K. blastocrithidii & WP_015390063.1 & \\
\hline 1.1.1.94 & Ca. K. crithidii & WP_015238529. & WAG + G \\
4.1.1.65 & Ca. K. desouzaii & WP_015396314. & WAG + G \\
& Ca. K. sorsogonicusi & AWD32452.1 & \\
\end{tabular}

G, modeling of heterogeneity of substitution rates using estimates following a discrete gamma distribution; F, fixed residue frequencies; CREPV and WAG, empirical amino acid substitution models as implemented in RAxML (see program documentation for details); 1.1.1.94, Glycerol-3-Phospahte dehydrogenase; 2.3.1.51, Glycerol-3-Phospahte acyltransferase; 2.7.7.41, Phosphatidic Acid cytidylyltransferase; 2.7.8.5, CDP-diacylglycerolGlycerol-3-Phospahte phosphatidyltransferase; 3.1.3.27.A, phosphatidylglycerophosphatase A; 4.1.1.65, Phosphatidylserine decarboxylase.

Table 2. GPL enzyme gene sequences found in A. deanei and S. culicis used for phylogenetic analysis.

\begin{tabular}{cccc}
\hline Enzyme & A. deanei Accession & S. culicis Accession & Substitution Model \\
\hline 1.1 .1 .8 & EPY26396.1 & EPY26225.1 & LG + G + F \\
2.3 .1 .51 & EPY39144.1 & EPY35625.1 & JTT + G + E \\
3.1 .1 .5 & EPY26987.1 & EPY27559.1 & LG + G + F \\
2.7 .7 .41 & EPY27658.1 & EPY27813.1 & VT + G + E \\
2.7 .8 .5 & EPY38995.1 & EPY20239.1 & VT + G + E \\
4.1 .1 .65 & EPY37752.1 & EPY26555.1 & JTT + G + E \\
1.1 .3 .21 & EPY42326.1 & EPY33132.1 & WAG + G + F \\
1.1 .5 .3 & EPY29427.1 & EPY28316.1 & WAG + G + E \\
2.1 .1 .17 & EPY36199.1 & EPY25191.1 & LG + G + E \\
2.3 .1 .15 & EPY32191.1 & EPY19897.1 & VT + G + F \\
2.7 .1 .107 & EPY19511.1 & EPY28592.1 & JTT + G + F \\
2.7 .1 .32 & EPY36410.1 & EPY24705.1 & VT + G + F \\
2.7 .1 .82 & EPY28885.1 & EPY29571.1 & JTT + G + E \\
2.7 .7 .14 & EPY43438.1 & EPY23528.1 & VT + G + F \\
2.7 .7 .15 & EPY32479.1 & EPY36580.1 & VT + G + F \\
2.7 .8 .1 & EPY25282.1 & EPY36363.1 & JTT + G + E \\
2.7 .8 .29 & EPY26426.1 & EPY26341.1 & VT + G + F \\
2.7 .8 .2 & EPY27385.1 & EPY22867.1 & VT + G + E \\
2.7 .8 .8 & EPY26426.1 & EPY26341.1 & VT + G + F \\
3.1 .3 .4 & EPY21603.1 & Not found & VT + G + E \\
3.1 .4 .46 & EPY26374.1 & EPY27334.1 & JTT + G + E
\end{tabular}

G, modeling of heterogeneity of substitution rates using estimates following a discrete gamma distribution F, fixed residue frequencies; E, empirical residue frequencies; LG, JTT, VT, and WAG, empirical amino acid substitution models as implemented in RAxML (see program documentation for details); 1.1.1.8, Glycerol-3Phospahte dehydrogenase; 1.1.3.21, Glycerol-3-Phospahte oxidase; 1.1.5.3, Glycerol-3-Phospahte dehydrogenase; 2.1.1.17, Phosphatidylethanolamine N-methyltransferase; 2.3.1.15, Glycerol-3-Phospahte acyltransferase; 2.3.1.51, Glycerol-3-Phospahte acyltransferase; 2.7.1.32, choline kinase; 2.7.1.82, ethanolamine kinase; 2.7.1.107, diacylglycerol kinase; 2.7.7.14, ethanolamine-phosphate cytidylyltransferase; 2.7.7.15, choline-phosphate cytidylyltransferase; 2.7.7.41, Phosphatidic Acid cytidylyltransferase; 2.7.8.1, ethanolaminephosphotransferase; 2.7.8.2 diacylglycerol cholinephosphotransferase; 2.7.8.29, phosphatidylserine synthase 2; 2.7.8.5, CDP-diacylglycerolGlycerol-3-Phospahte phosphatidyltransferase; 2.7.8.8, CDP-diacylglycerol-serine phosphatidyltransferase; 3.1.1.5 lysophospholipase I; 3.1.3.4, Phosphatidic Acid phosphatase; 3.1.4.46, glycerophosphodiester phosphodiesterase; 4.1.1.65, Phosphatidylserine decarboxylase.

For each bacterial dataset, multiple sequence alignments (MSA) were performed with Mafft v.7.313 [46], and evolutionary models were obtained with ModelGenerator [47] (see Tables 1 and 2). Maximum likelihood phylogenetic inferences were performed by RAxML v.8.2.9 [48] on a Linux computer (BullX B700) cluster using five nodes, each one carrying two Intel Xeon E5-2695v2 Ivy Bridge (24-core) processors, totaling 120 tasks processed by the MPI version of RAxML. One hundred different best tree searches were performed, and the tree with best likelihood found was kept. RAxML's rapid bootstrap was performed with 100 pseudoreplicates, and support is only shown for branches with values of at least 50. The final tree was drawn and basically formatted by MEGA 7.0.21 [49]. 
For the eukaryotic datasets, protein alignments were performed using MUSCLE v. 3.8.31 [50], and phylogenetic analyses were performed using RAxML, using gammadistributed heterogeneity of substitution rates and automatic empirical model selection. Number of bootstrap pseudoreplicates was also automatically selected by the program, ensuring that at least 100 pseudoreplicates were performed. Trypanosomatid trees were drawn and edited in Dendroscope [51], and final cosmetic adjustments were performed with Inkscape (https:/ /inkscape.org/, accessed on 14 October 2021).

Supplementary Materials: The following are available online at https:/ /www.mdpi.com/article/10 .3390/pathogens11010041/s1, Table S1: Enzyme list; Figure S1: Maximum likelihood phylogenetic tree for enzymes Glycerol-3-Phospahte dehydrogenase (1.1.1.94) using E. coli sequence as the query for sequence selection; Figure S2: Maximum likelihood phylogenetic tree for enzymes Glycerol-3Phospahte acyltransferase (2.3.1.51) using E. coli sequence as the query for sequence selection; Figure S3: Maximum likelihood phylog enetic tree for enzymes Phosphatidic Acid cytidylyltransferase (2.7.7.41) using E. coli sequence as the query for sequence selection; Figure S4: Maximum likelihood phylogenetic tree for enzymes CDP-DAG- Glycerol-3-Phospahte phosphatidyltransferase (2.7.8.5) using E. coli's sequence as the query for sequence selection; Figure S5: Maximum likelihood phylogenetic tree for enzymes phosphatidylglycerophosphatase A (3.1.3.27_A) using E. coli sequence as the query for sequence selection; Figure S6: Maximum likelihood phylogenetic tree for enzymes Phosphatidylserine decarboxylase (4.1.1.65), using E. coli's sequence as the query for sequence selection; Figure S7: Close-up details maximum-likelihood phylogenetic tree of enzyme Glycerol-3-Phospahte dehydrogenase (1.1.1.8), focusing on the clades containing trypanosomatid sequences; Figure S8: Close-up details maximum-likelihood phylogenetic tree of enzyme Glycerol-3-Phospahte oxidase (1.1.3.21), focusing on the clades containing trypanosomatid sequences; Figure S9: Close-up details maximum-likelihood phylogenetic tree of enzyme Phosphatidic Acid cytidylyltransferase (2.7.7.41), focusing on the clades containing trypanosomatid sequences; Figure S10: Glycerophospholipid (GPL) metabolism in regular trypanosomatids (RT), symbiont harboring trypanosomatid (SHT), and trypanosomatid proteobacterial endosymbiont (TPE).

Author Contributions: Conceptualization, A.C.d.A.-M., J.M.P.A. and M.C.M.M.; methodology, A.C.d.A.-M., K.O. and J.M.P.A.; formal analysis, A.C.d.A.-M., K.O. and J.M.P.A.; investigation, A.C.d.A.-M., K.O. and J.M.P.A.; resources, W.d.S., A.T.R.d.V., J.M.P.A. and M.C.M.M.; writingoriginal draft preparation, A.C.d.A.-M. and M.C.M.M.; writing-review and editing, A.C.d.A.-M., W.d.S., J.M.P.A. and M.C.M.M.; visualization, A.C.d.A.-M., K.O. and J.M.P.A.; supervision, W.S, A.T.R.d.V., M.M.G.T., E.P.C. and M.C.M.M.; project administration, A.C.d.A.-M., J.M.P.A. and M.C.M.M.; funding acquisition, W.d.S., A.T.R.d.V., J.M.P.A. and M.C.M.M. All authors have read and agreed to the published version of the manuscript.

Funding: This research was funded by Conselho Nacional de Desenvolvimento Científico e Tecnológico (CNPq), grant numbers: 405168/2016-0, 305335/2018-9; Fundação de Amparo à Pesquisa do Estado do Rio de Janeiro (FAPERJ), grant numbers: E-26/202.917/2017, E-26/201.011/2021; São Paulo Research Foundation (FAPESP), grant number: \#2013/14622-3.

Institutional Review Board Statement: Not applicable.

Informed Consent Statement: Not applicable.

Acknowledgments: We would like to thank to FAPERJ, FAPESP, and CNPp for financial support.

Conflicts of Interest: The authors declare no conflict of interest.

\section{References}

1. De Bary, A. Die Mycetozoen. Ein Beitrag zur Kenntnis der niedersten Thiere. Z. Wiss. Zool. 1859, 10, 88-175.

2. Teixeira, M.M.; Borghesan, T.C.; Ferreira, R.C.; Santos, M.A.; Takata, C.S.; Campaner, M.; Nunes, V.L.B.; Milder, R.V.; de Souza, W.; Camargo, E.P. Phylogenetic Validation of the Genera Angomonas and Strigomonas of Trypanosomatids Harboring Bacterial Endosymbionts with the Description of New Species of Trypanosomatids and of Proteobacterial Symbionts. Protist 2011, 162, 503-524. [CrossRef]

3. Votýpka, J.; Kostygov, A.Y.; Kraeva, N.; Grybchuk-Ieremenko, A.; Tesařová, M.; Grybchuk, D.; Lukeš, J.; Yurchenko, V. Kentomonas gen. n., a New Genus of Endosymbiont-containing Trypanosomatids of Strigomonadinae subfam. n. Protist 2014, 165, 825-838. [CrossRef] [PubMed] 
4. $\quad$ Alves, J.M.; Serrano, M.G.; Silva, F.M.D.; Voegtly, L.J.; Matveyev, A.V.; Teixeira, M.M.; Camargo, E.P.; Buck, G.A. Genome Evolution and Phylogenomic Analysis of Candidatus Kinetoplastibacterium, the Betaproteobacterial Endosymbionts of Strigomonas and Angomonas. Genome Biol. Evol. 2013, 5, 338-350. [CrossRef]

5. Silva, F.M.; Kostygov, A.Y.; Spodareva, V.V.; Butenko, A.; Tossou, R.; Lukeš, J.; Yurchenko, V.; Alves, J.M.P. The reduced genome of Candidatus Kinetoplastibacterium sorsogonicusi, the endosymbiont of Kentomonas sorsogonicus (Trypanosomatidae): Loss of the haem-synthesis pathway. Parasitology 2018, 145, 1287-1293. [CrossRef] [PubMed]

6. Kostygov, A.Y.; Butenko, A.; Nenarokova, A.; Tashyreva, D.; Flegontov, P.; Lukeš, J.; Yurchenko, V. Genome of Ca. Pandoraea novymonadis, an Endosymbiotic Bacterium of the Trypanosomatid Novymonas esmeraldas. Front. Microbiol. 2017, 8, 1940. [CrossRef]

7. Martin, W.F.; Garg, S.; Zimorski, V. Endosymbiotic theories for eukaryote origin. Philos. Trans. R. Soc. B 2015, $370,20140330$. [CrossRef]

8. Freymuller, E.; Camargo, E.P. Ultrastructural Differences between Species of Trypanosomatids with and Without Endosymbionts. J. Protozool. 1981, 28, 175-182. [CrossRef]

9. Gadelha, C.; Wickstead, B.; Souza, W.D.; Gull, K.; Cunha-E-Silva, N. Cryptic Paraflagellar Rod in Endosymbiont-Containing Kinetoplastid Protozoa. Eukaryot. Cell 2005, 4, 516-525. [CrossRef] [PubMed]

10. Chang, K.P. Reduced growth of Blastocrithidia culicis and Crithidia oncopelti freed of intracellular symbiotes by chloramphenicol. J. Protozool. 1975, 22, 271-276. [CrossRef]

11. Esteves, M.J.; Andrade, A.F.; Angluster, J.; de Souza, W.; Mundim, M.H.; Roitman, I.; Perreira, M.E. Cell surface carbohydrates in Crithidia deanei: Influence of the endosymbiote. Eur. J. Cell Biol. 1982, 26, 244-248. [PubMed]

12. Catta-Preta, C.; Nascimento, M.; Garcia, M.; Saraiva, E.; Motta, M.; Meyer-Fernandes, J. The presence of a symbiotic bacterium in Strigomonas culicis is related to differential ecto-phosphatase activity and influences the mosquito-protozoa interaction. Int. J. Parasitol. 2013, 43, 571-577. [CrossRef]

13. D'avila-Levy, C.M.; Silva, B.A.; Hayashi, E.A.; Vermelho, A.B.; Alviano, C.S.; Saraiva, E.M.; Branquinha, M.H.; Santos, A.L.S. Influence of the endosymbiont of Blastocrithidia culicis and Crithidia deanei on the glycoconjugate expression and on Aedes aegypti interaction. FEMS Microbiol. Lett. 2005, 252, 279-286. [CrossRef]

14. Mundim, M.H.; Roitman, I.; Hermans, M.A.; Kitajima, E.W. Simple Nutrition of Crithidia deanei, a Reduviid Trypanosomatid with an Endosymbiont. J. Protozool. 1974, 21, 518-521. [CrossRef]

15. Camargo, E.P.; Freymuller, E. Endosymbiont as supplier of ornithine carbamoyltransferase in a trypanosomatid. Nature 1977, 270, 52-53. [CrossRef] [PubMed]

16. Salzman, T.A.; Batlle, A.D.C.; Angluster, J.; Souza, W.D. Heme synthesis in Crithidia deanei: Influence of the endosymbiote. Int. J. Biochem. 1985, 17, 1343-1347. [CrossRef]

17. Alves, J.M.P.; Voegtly, L.; Matveyev, A.V.; Lara, A.M.; Silva, F.M.D.; Serrano, M.G.; Buck, G.A.; Teixeira, M.M.G.; Camaargo, E.P. Identification and Phylogenetic Analysis of Heme Synthesis Genes in Trypanosomatids and Their Bacterial Endosymbionts. PLoS ONE 2011, 6, e23518. [CrossRef] [PubMed]

18. Alves, J.M.; Klein, C.C.; Silva, F.D.; Costa-Martins, A.G.; Serrano, M.G.; Buck, G.A.; Vasconcelos, A.T.R.; Sagot, M.-F.; Teixeira, M.M.G.; Motta, M.C.M.; et al. Endosymbiosis in trypanosomatids: The genomic cooperation between bacterium and host in the synthesis of essential amino acids is heavily influenced by multiple horizontal gene transfers. BMC Evol. Biol. 2013, 13, 190. [CrossRef]

19. Klein, C.C.; Alves, J.M.P.; Serrano, M.G.; Buck, G.A.; Vasconcelos, A.T.R.; Sagot, M.-F.; Teixeira, M.M.G.; Camargo, E.P.; Motta, M.C.M. Biosynthesis of Vitamins and Cofactors in Bacterium-Harbouring Trypanosomatids Depends on the Symbiotic Association as Revealed by Genomic Analyses. PLoS ONE 2013, 8, e79786. [CrossRef]

20. Motta, M.C.M.; Martins, A.C.D.A.; Souza, S.S.A.D.; Catta-Preta, C.M.C.; Silva, R.; Klein, C.C.; de Almeida, L.G.P.; de Lima Cunha, O.; Ciapina, L.P.; Brocchi, M.; et al. Predicting the Proteins of Angomonas deanei, Strigomonas culicis and Their Respective Endosymbionts Reveals New Aspects of the Trypanosomatidae Family. PLoS ONE 2013, 8, e60209.

21. Azevedo-Martins, A.C.; Machado, A.C.L.; Klein, C.C.; Ciapina, L.; Gonzaga, L.; Vasconcelos, A.T.R.; Sagot, M.F.; de Souza, W.; Einicker-Lamas, M.; Galina, A.; et al. Mitochondrial respiration and genomic analysis provide insight into the influence of the symbiotic bacterium on host trypanosomatid oxygen consumption. Parasitology 2014, 142, 352-362. [CrossRef] [PubMed]

22. Loyola-Machado, A.C.; Azevedo-Martins, A.C.; Catta-Preta, C.M.C.; Souza, W.D.; Galina, A.; Motta, M.C.M. The Symbiotic Bacterium Fuels the Energy Metabolism of the Host Trypanosomatid Strigomonas culicis. Protist 2017, 168, 253-269. [CrossRef]

23. Azevedo-Martins, A.C.Z.D.; Frossard, M.L.; Souza, W.D.; Einicker-Lamas, M.; Motta, M.C.M. Phosphatidylcholine synthesis in Crithidia deanei: The influence of the endosymbiont. FEMS Microbiol. Lett. 2007, 275, 229-236. [CrossRef]

24. Dowhan, W. Understanding phospholipid function: Why are there so many lipids? J. Biol. Chem. 2017, 292, 10755-10766. [CrossRef] [PubMed]

25. Yang, Y.; Lee, M.; Fairn, G.D. Phospholipid subcellular localization and dynamics. J. Biol. Chem. 2018, 293, 6230-6240. [CrossRef] [PubMed]

26. Tachado, S.D.; Mazhari-Tabrizi, R.; Schofield, L. Specificity in signal transduction among glycosylphosphatidylinositols of Plasmodium falciparum, Trypanosoma brucei, Trypanosoma cruzi and Leishmania spp. Parasite Immunol. 1999, 21, 609-617. [CrossRef] [PubMed] 
27. Almeida-Amaral, E.E.; Cardoso, V.C.; Francioli, F.G.; Meyer-Fernandes, J.R. Leishmania amazonensis: Heme stimulates $\left(\mathrm{Na}^{+}+\mathrm{K}^{+}\right)$ ATPase activity via phosphatidylinositol-specific phospholipase C/protein kinase C-like (PI-PLC/PKC) signaling pathways. Exp. Parasitol. 2010, 124, 436-441. [CrossRef]

28. Smith, T.K.; Bütikofer, P. Lipid metabolism in Trypanosoma brucei. Mol. Biochem. Parasitol. 2010, 172, 66-79. [CrossRef]

29. Ratti, S.; Ramazzotti, G.; Faenza, I.; Fiume, R.; Mongiorgi, S.; Billi, A.M.; McCubrey, J.A.; Suh, P.-G.; Manzoli, L.; Cocco, L.; et al. Nuclear inositide signaling and cell cycle. Adv. Biol. Regul. 2018, 67, 1-6. [CrossRef]

30. Racagni, G.; Lema, M.G.D.; Domenech, C.E.; Domenech, E.E.M.D. Phospholipids in Trypanosoma cruzi: Phosphoinositide composition and turnover. Lipids 1992, 27, 275-278. [CrossRef] [PubMed]

31. Patnaik, P.K.; Field, M.C.; Menon, A.K.; Cross, G.A.; Yee, M.C.; Bütikofer, P. Molecular species analysis of phospholipids from Trypanosoma brucei bloodstream and procyclic forms. Mol. Biochem. Parasitol. 1993, 58, 97-105. [CrossRef]

32. Zhang, K.; Beverley, S.M. Phospholipid and sphingolipid metabolism in Leishmania. Mol. Biochem. Parasitol. 2010, 170, 55-64. [CrossRef]

33. Serricchio, M.; Bütikofer, P. Trypanosoma brucei: A model micro-organism to study eukaryotic phospholipid biosynthesis. FEBS J. 2011, 278, 1035-1046. [CrossRef]

34. Biagiotti, M.; Dominguez, S.; Yamout, N.; Zufferey, R. Lipidomics and anti-trypanosomatid chemotherapy. Clin. Transl. Med. 2017, 6, 27. [CrossRef]

35. Palmié-Peixoto, I.V.; Rocha, M.R.; Urbina, J.A.; Souza, W.; Einicker-Lamas, M.; Motta, M.C.M. Effects of sterol biosynthesis inhibitors on endosymbiont-bearing trypanosomatids. FEMS Microbiol. Lett. 2006, 255, 33-42. [CrossRef]

36. Hindahl, M.S.; Iglewski, B.H. Isolation and characterization of the Legionella pneumophila outer membrane. J. Bacteriol. 1984, 159, 107-113. [CrossRef] [PubMed]

37. Albelo, S.T.; Domenech, C.E. Carbons from choline present in the phospholipids of Pseudomonas aeruginosa. FEMS Microbiol. Lett. 2006, 156, 271-274. [CrossRef]

38. Rudder, K.E.D.; Thomas-Oates, J.E.; Geiger, O. Rhizobium meliloti mutants deficient in phospholipid N-methyltransferase still contain phosphatidylcholine. J. Bacteriol. 1997, 179, 6921-6928. [CrossRef]

39. Minder, A.C.; Rudder, K.E.E.D.; Narberhaus, F.; Fischer, H.-M.; Hennecke, H.; Geiger, O. Phosphatidylcholine levels in Bradyrhizobium japonicum membranes are critical for an efficient symbiosis with the soybean host plant. Mol. Microbiol. 2004, 39, 1186-1198. [CrossRef]

40. Aktas, M.; Wessel, M.; Hacker, S.; Klüsener, S.; Gleichenhagen, J.; Narberhaus, F. Phosphatidylcholine biosynthesis and its significance in bacteria interacting with eukaryotic cells. Eur. J. Cell Biol. 2010, 89, 888-894. [CrossRef]

41. Sohlenkamp, C.; Geiger, O. Bacterial membrane lipids: Diversity in structures and pathways. FEMS Microbiol. Rev. 2015, 40, 133-159. [CrossRef]

42. Engstrom, E.M.; Ehrhardt, D.W.; Mitra, R.M.; Long, S.R. Pharmacological Analysis of Nod Factor-Induced Calcium Spiking in Medicago truncatula. Evidence for the Requirement of Type IIA Calcium Pumps and Phosphoinositide Signaling. Plant Physiol. 2002, 128, 1390-1401. [CrossRef]

43. Wais, R.J.; Keating, D.H.; Long, S.R. Structure-Function Analysis of Nod Factor-Induced Root Hair Calcium Spiking in RhizobiumLegume Symbiosis. Plant Physiol. 2002, 129, 211-224. [CrossRef] [PubMed]

44. Azevedo-Martins, A.C.D.; Alves, J.M.; Mello, F.G.D.; Vasconcelos, A.T.R.; Souza, W.D.; Einicker-Lamas, M.; Motta, M.C.M. Biochemical and phylogenetic analyses of phosphatidylinositol production in Angomonas deanei, an endosymbiont-harboring trypanosomatid. Parasite Vectors 2015, 8, 247. [CrossRef]

45. Aslett, M.; Aurrecoechea, C.; Berriman, M.; Brestelli, J.; Brunk, B.P.; Carrington, M.; Depledge, D.P.; Fischer, S.; Gajria, B.; Gao, X.; et al. TriTrypDB: A functional genomic resource for the Trypanosomatidae. Nucleic Acids Res. 2009, 38 (Suppl. 1), D457-D462. [CrossRef]

46. Katoh, K.; Standley, D.M. MAFFT Multiple Sequence Alignment Software Version 7: Improvements in Performance and Usability. Mol. Biol. Evol. 2013, 30, 772-780. [CrossRef]

47. Keane, T.M.; Creevey, C.J.; Pentony, M.M.; Naughton, T.J.; Mclnerney, J.O. Assessment of methods for amino acid matrix selection and their use on empirical data shows that ad hoc assumptions for choice of matrix are not justified. BMC Evol. Biol. 2006, 6, 29. [CrossRef]

48. Stamatakis, A. RAxML version 8: A tool for phylogenetic analysis and post-analysis of large phylogenies. Bioinformatics 2014, 30, 1312-1313. [CrossRef]

49. Kumar, S.; Nei, M.; Dudley, J.; Tamura, K. MEGA: A biologist-centric software for evolutionary analysis of DNA and protein sequences. Brief Bioinform. 2008, 9, 299-306. [CrossRef] [PubMed]

50. Edgar, R.C. Search and clustering orders of magnitude faster than BLAST. Bioinformatics 2010, 26, 2460-2461. [CrossRef] [PubMed]

51. Huson, D.H.; Scornavacca, C. Dendroscope 3: An Interactive Tool for Rooted Phylogenetic Trees and Networks. Syst. Biol. 2012, 61, 1061-1067. [CrossRef]

52. Wang, L.-H.; Lee, H.-H.; Fang, L.-S.; Mayfield, A.B.; Chen, C.-S. Fatty Acid and Phospholipid Syntheses Are Prerequisites for the Cell Cycle of Symbiodinium and Their Endosymbiosis within Sea Anemones. PLoS ONE 2013, 8, e72486. [CrossRef]

53. Chen, H.-K.; Song, S.-N.; Wang, L.-H.; Mayfield, A.B.; Chen, Y.-J.; Chen, W.-N.U.; Chen, C.-S. A Compartmental Comparison of Major Lipid Species in a Coral-Symbiodinium Endosymbiosis: Evidence that the Coral Host Regulates Lipogenesis of Its Cytosolic Lipid Bodies. PLoS ONE 2015, 10, e0132519. [CrossRef] [PubMed] 
54. Hill, L.J.; Paradas, W.C.; Willemes, M.J.; Pereira, M.G.; Salomon, P.S.; Mariath, R.; Moura, R.L.; Atella, G.C.; Farina, M.; Amado-Filho, G.M.; et al. Acidification-induced cellular changes in Symbiodinium isolated from Mussismilia braziliensis. PLoS ONE 2019, 14, e0220130. [CrossRef]

55. Wilderman, P.J.; Vasil, A.I.; Martin, W.E.; Murphy, R.C.; Vasil, M.L. Pseudomonas aeruginosa Synthesizes Phosphatidylcholine by Use of the Phosphatidylcholine Synthase Pathway. J. Bacteriol. 2002, 184, 4792-4799. [CrossRef]

56. Comerci, D.J.; Altabe, S.; Mendoza, D.D.; Ugalde, R.A. Brucella abortus Synthesizes Phosphatidylcholine from Choline Provided by the Host. J. Bacteriol. 2006, 188, 1929-1934. [CrossRef] [PubMed]

57. Wessel, M.; Klüsener, S.; Gödeke, J.; Fritz, C.; Hacker, S.; Narberhaus, F. Virulence of Agrobacterium tumefacien srequires phosphatidylcholine in the bacterial membrane. Mol. Microbiol. 2006, 62, 906-915. [CrossRef]

58. Basu, S.S.; York, J.D.; Raetz, C.R. A Phosphotransferase That Generates Phosphatidylinositol 4-Phosphate (PtdIns-4-P) from Phosphatidylinositol and Lipid A in Rhizobium leguminosarum. J. Biol. Chem. 1999, 274, 11139-11149. [CrossRef] [PubMed]

59. Pizarro-Cerdá, J.; Cossart, P. Subversion of phosphoinositide metabolism by intracellular bacterial pathogens. Nat. Cell Biol. 2004, 6, 1026-1033. [CrossRef] [PubMed]

60. Yao, J.; Rock, C.O. Phosphatidic acid synthesis in bacteria. BBA-Mol. Cell Biol. Lipids 2013, 1831, 495-502. [CrossRef]

61. Lastovetsky, O.A.; Gaspar, M.L.; Mondo, S.J.; Labutti, K.M.; Sandor, L.; Grigoriev, I.V.; Henry, S.A.; Pawlowska, T.E. Lipid metabolic changes in an early divergent fungus govern the establishment of a mutualistic symbiosis with endobacteria. Proc. Natl. Acad. Sci. USA 2016, 113, 15102-15107. [CrossRef] [PubMed]

62. Tielens, A.G.; Rotte, C.; Hellemond, J.J.V.; Martin, W. Mitochondria as we don't know them. Trends Biochem. Sci. 2002, 27, 564-572. [CrossRef]

63. Catta-Preta, C.M.C.; Brum, F.L.; Silva, C.C.D.; Zuma, A.A.; Elias, M.C.; Souza, W.D.; Schenkman, S.; Motta, M.C.M. Endosymbiosis in trypanosomatid protozoa: The bacterium division is controlled during the host cell cycle. Front. Microbiol. 2015, 6, 520. [CrossRef]

64. Wendel, A.A.; Lewin, T.M.; Coleman, R.A. G3Pacyltransferases: Rate limiting enzymes of triacylglycerol biosynthesis. BBA-Mol. Cell Biol. Lipids 2009, 1791, 501-506. [CrossRef]

65. Brancucci, N.M.; Gerdt, J.P.; Wang, C.; Niz, M.D.; Philip, N.; Adapa, S.R.; Zhang, M.; Hitz, E.; Niederwieser, I.; Boltryk, S.D.; et al. Lysophosphatidylcholine Regulates Sexual Stage Differentiation in the Human Malaria Parasite Plasmodium falciparum. Cell 2017, 171, 1532-1544. [CrossRef] [PubMed]

66. Booth, L. Investigating the Kennedy Pathway: Phosphatidylcholine and Phosphatidylethanolamine Biosynthesis in Trypanosoma cruzi. In Annals, Proceedings of the XXXV Reunião Anual da Sociedade Brasileira de Protozoologia and XVI Reunião Anual sobre Pesquisa básica em Doença de Chagas, Caxambu, Brazil, 4-6 November 2019; Sociedade Brasileira de Protozoologia: São Paulo, Brazil, 2019; p. 12.

67. Bibis, S.S.; Dahlstrom, K.; Zhu, T.; Zufferey, R. Characterization of Leishmania major phosphatidylethanolamine methyltransferases LmjPEM1 and LmjPEM2 and their inhibition by choline analogs. Mol. Biochem. Parasit. 2014, 196, 90-99. [CrossRef] [PubMed]

68. Michel, A.H.; Kornmann, B. The ERMES complex and ER-mitochondria connections. Biochem. Soc. Trans. 2012, 40, 445-450. [CrossRef]

69. Schlame, M. Thematic Review Series: Glycerolipids. Cardiolipin synthesis for the assembly of bacterial and mitochondrial membranes. J. Lipid Res. 2008, 49, 1607-1620. [CrossRef] [PubMed]

70. Arias-Cartin, R.; Grimaldi, S.; Arnoux, P.; Guigliarelli, B.; Magalon, A. Cardiolipin binding in bacterial respiratory complexes: Structural and functional implications. BBA-Bioenergetics 2012, 1817, 1937-1949. [CrossRef]

71. Carranza, G.; Angius, F.; Ilioaia, O.; Solgadi, A.; Miroux, B.; Arechaga, I. Cardiolipin plays an essential role in the formation of intracellular membranes in Escherichia coli. BBA-Biomembranes 2017, 1859, 1124-1132. [CrossRef] [PubMed]

72. Penha, L.L.; Hoffmann, L.; Souza, S.S.A.D.; Martins, A.C.D.A.; Bottaro, T.; Prosdocimi, F.; Faffe, D.S.; Motta, M.S.M.; Ürményi, T.P.; Silva, R. Symbiont modulates expression of specific gene categories in Angomonas deanei. Mem. Inst. Oswaldo Cruz. 2016, 111, 686-691. [CrossRef]

73. Brunoro, G.V.; Menna-Barreto, R.F.; Garcia-Gomes, A.S.; Boucinha, C.; Lima, D.B.; Carvalho, P.C.; Teixeira-Ferreira, A.; Trugilho, M.R.O.; Perales, J.; Schwämmle, V.; et al. Quantitative Proteomic Map of the Trypanosomatid Strigomonas culicis: The Biological Contribution of its Endosymbiotic Bacterium. Protist 2019, 170, 125698. [CrossRef]

74. Catta-Preta, C.M.C.; dos Santos Pascoalino, B.; de Souza, W.; Mottram, J.C.; Motta, M.C.M.; Schenkman, S. Reduction of Tubulin Expression in Angomonas deanei by RNAi Modifies the Ultrastructure of the Trypanosomatid Protozoan and Impairs Division of Its Endosymbiotic Bacterium. J. Euk. Microbiol. 2016, 63, 794-803. [CrossRef]

75. Gonçalves, C.S.; Catta-Preta, C.M.C.; Repolês, B.; Mottram, J.C.; de Souza, W.; Machado, C.R.; Motta, M.C.M. Importance of Angomonas deanei KAP4 for kDNA arrangement, cell division and maintenance of the host-bacterium relationship. Sci. Rep. 2021, 11, 9210. [CrossRef] 